\title{
Post-collisional Orogenic Magmatism Involves Melting of Blueschist Stored in Shallow Lithosphere
}

\author{
Yu Wang ${ }^{1,2}$, Stephen F. Foley ${ }^{2}$, Dejan PRelević ${ }^{3,4}$
} AND YIGANG XU ${ }^{1,5}$

${ }^{1}$ State Key Laboratory of Isotope Geochemistry, Guangzhou Institute of Geochemistry, Chinese Academy of Sciences, China

${ }^{2}$ Department of Earth and Environmental Sciences and CCFS, Macquarie University Australia

${ }^{3}$ Faculty of Mining and Geology, Belgrade University, Belgrade, Serbia

${ }^{4}$ Institute for Geosciences, University of Mainz, Germany

${ }^{5}$ School of Earth and Planetary Sciences, University of

Chinese Academy of Sciences, Beijing, China

Basalts, gabbros and sediments in subducted oceanic lithospheric plate are metamorphosed into blueschists at relatively shallow depths of $20-50 \mathrm{~km}$ (0.6-1.2 GPa). At higher pressures in deep subduction zones, they are commonly transformed into garnet amphibolites and eclogites before melting could occur. However, not all blueschists are destined to be subducted deeply enough for this conventional metamorphic pattern to occur. In regions with small ocean plates and continental blocks such as the Mediterranean in the Cenozoic and modern Indonesia, many blueschists may be imbricated as blueschist facies mélange intercalated with depleted peridotites at shallow depth, in mantle lithosphere that is newly formed during the amalgamation of these small continental blocks and oceans. This new lithosphere is thought to be the source region of many volcanic rocks, particularly potassium-rich post-collisional orogenic lavas that are erupted just 20-50 million years after their lithospheric source was formed. Therefore, despite the hitherto deeply-rooted notion that blueschists can never reach melting conditions, it is very likely that melting of blueschists at low pressures in mixed lithosphere of this type could occur, especially in post-collisional orogenic settings.

Here we present an experimental study of three different natural Turkish blueschists which simulate blueschist $\rightarrow$ eclogite dehydration melting at $800-850^{\circ} \mathrm{C}, 2 \mathrm{GPa}$. Unlike many studies of eclogite, blueschist preserves the original volatile contents and mineralogy of low-temperature rocks while following the prograde path to melting. We have investigated the phase and melting relations, compositional variations of minerals and melts, and potential implications of blueschist melting for understanding the genesis of postcollisional orogenic magmatism. 